\title{
Study of fracture shaft of Femur and its outcome treated with K- Nail in Manipal Teaching Hospital
}

\author{
Krishna Sapkota ${ }^{1}$, Niraj Ranjeet ${ }^{1}$, Pratyenta Raj Onta $^{2}$, Pabin Thapa ${ }^{2}$, \\ Upendra Jung Thapa ${ }^{2}$ \\ ${ }^{1}$ Assistant Professor, Department of Orthopedics, Manipal Teaching Hospital, Phulbari, Pokhara, Nepal, ${ }^{2}$ Lecturer, \\ Department of Orthopedics, Manipal Teaching Hospital, Phulbari, Pokhara, Nepal
}

Background: Intramedullary interlocking nail is commonly accepted standard treatment in fracture shaft of femur. Its cost, technique, necessity of fracture table and image intensifier make it difficult in using for such cases where facilities are not available. In developing countries like Nepal open Kuntscher nailing is still an option for treating fracture shaft of femur. Its results and outcomes are comparable to that of intramedullary interlocking nails. Aims and Objectives: This study was undertaken to evaluate the outcome of Kuntscher nailing in fracture shaft of femur with regards to operative duration, union, infection, limblength, and range of motion of knee and hip joints. Materials and Methods: This retrospective study included seventy-six patients with fracture shaft of femur. This study was conducted for a period from December 2014 to December 2017. The study outcome was assessed in terms of operative time duration, union, infection, limb-length, and range of motion of knee and hip joints. Results: Seventy six patients with fracture shaft of femur with mean age of 32.36 years ranging from 15 to 65 years were included in the study. Operation duration ranges from 55 to 95 minutes, with average healing time of 17 weeks. Wound infection was seen in $5 \%$ cases, with not much limb length discrepancy and knee range of motion $100-135$ degree achieved by the end of 9 months in more than $95 \%$ cases. Conclusion: Kuntscher nail is still a relevant option for treatment of fracture shaft of femur with good functional and clinical outcome.

Key word: Femur fracture; Kuntscher nail; Shaft of femur fracture
Access this article online

\section{Website:}

http://nepjol.info/index.php/AJMS DOI: 10.3126/ajms.v9i6.20587

E-ISSN: 2091-0576 P-ISSN: $2467-9100$

\section{INTRODUCTION}

Fracture shaft of femur is one of the common fractures in adults that result from high velocity injuries. Providing rigid and stable fixation in anatomical position helps in early mobilization of the patients. Closed intramedullary interlocking nail is the gold standard treatment for fracture shaft of femur which helps in maintaining its lengths and control rotational deformity. ${ }^{1-3}$

Gerhard Kuntscher introduced Kuntscher Nail (K-Nail) in 1940, since then it is widely used for fracture shaft of femur. ${ }^{4}$ Due to its poor control for rotational deformity it is not used for distal fractures, highly comminuted fractures.
Interlocking systems were developed for controlling the rotational deformities for which intramedullary interlocking nail were developed along with development of image intensifier and fracture tables.

However $\mathrm{K}$ nail is still an option for treatment of fracture shaft of femur where patients cannot afford or where we have lack of special instrumentation and image intensifier. ${ }^{5,6}$ The current study included seventy six patients treated by $\mathrm{K}$ nail for the past six years in Manipal teaching hospital. The aim of the study was to review the outcome of patients treated by $\mathrm{K}$ nail. Considering its limited indication can itbe used where patients cannot afford or where we have lack of special instruments and image intensifier. 


\section{MATERIALS AND METHODS}

We studied 76 patients with fracture shaft of femur treated with K- nail in Manipal Teaching Hospital from December 2014 to December 2017. Fracture shaft of femur involving the proximal and middle third of bone were included in study. Open fractures, severely comminuted fractures, and those involving distal $1 / 3$ were excluded.

All the cases were done in lateral position by open methods. Fracture site opened, and fracture ends exposed cleaned and canal was reamed. Appropriate size $\mathrm{K}$ nail inserted by retrograde method through the proximal fragments. Fracture reduction done under direct vision rotational alignment corrected seeing lineaaspara and fracture pattern and nail inserted distally. Wound closed over negative suction drain. IV Antibiotics were given for 5 days.

\section{RESULTS}

A total of 76 patients who met the inclusion criteria were included in the study. Demographic profiles are shown in Table 1.

The most common mechanism of injury was fall from tree and hill, followed by RTA and other injuries like fall on ground, while playing, blunt trauma. Twenty four patients had associated injuries, 14 had Head injuries, 13 had upper limb injuries and 7 had lower limb injuries, 10 patients had multiple fractures associated with head injuries in 5 cases. The most common fracture is transverse fracture; other fracture features are there in table 2 .

Mean time of presentation to hospital was within 24 hours in more than 95 percent cases. Average duration of surgery was $68.99 \pm 11.03$ minutes. Blood transfusion required in 60 percent cases. All wound healed by 14 days.Superficial infection seen in $3(3.9 \%)$ cases that subside after regular dressing and oral antibiotics and in one $(1.3 \%)$ case pts had deep infection that requires removal of implant.

Full weight bearing start as pts had visible callus in $\mathrm{x}$ - ray (Figures 1 and 2). (Mean 17.17 \pm 1.12 ) Fracture heals on an average of $17.46 \pm 3.87$ weeks range from $12-30$ weeks. In 14 cases limb shorten by $1-2 \mathrm{~cm}$. In 2 patients limb shorten by $3 \mathrm{~cm}$. Knee range of motion reach $100^{\circ}-135^{\circ}$ by end of 9 months. One patient had varus by $8^{\circ}$ which is acceptable.

\section{DISCUSSION}

Kuntscher Nail was introduced by Gerhard Kuntscher in 1940, after that it become popular fixation method for facture shaft of femur. Due to it poor control in rotational deformity, in many tertiary center $\mathrm{K}$ nail is no longer used. Its indication is limited to transverse fracture in isthmus. Closed

\begin{tabular}{lc}
\multicolumn{2}{l}{ Table 1: Demographic variables } \\
\hline Variables & Results \\
\hline Age of patients & $32.36 \pm 14.48(15-65 \mathrm{yrs})$ \\
Sex of patients & \\
Male & $28(36.8 \%)$ \\
Female & $48(63.2 \%)$ \\
\hline
\end{tabular}

\begin{tabular}{llcc} 
Table 2: Fracture features \\
\hline Variables & Definition & \multicolumn{2}{c}{ Patients } \\
\cline { 3 - 4 } & & $\begin{array}{c}\text { No. of } \\
\text { cases }\end{array}$ & Percentage (\%) \\
\hline Mechanism of & RTA & 29 & 38.16 \\
Injury & Fall from & 34 & 44.74 \\
& trees, hills & 13 & 17.11 \\
Side of fracture & Others & 39 & 51.3 \\
& Right & 37 & 48.7 \\
Pattern of & Left & 33 & 43.4 \\
fracture & Transverse & & \\
& Short oblique & 30 & 39.5 \\
& Comminuted & 13 & 17.1 \\
\hline
\end{tabular}

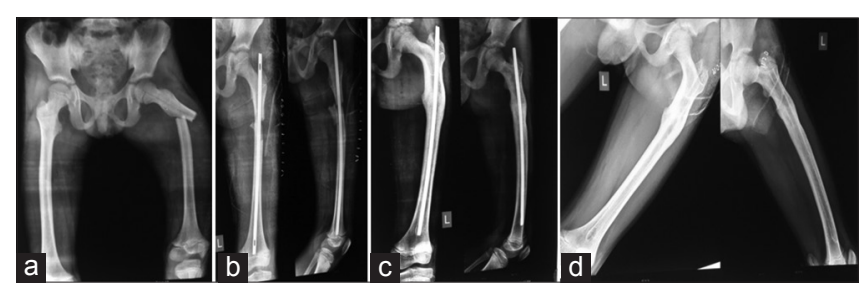

Figure 1: Seventeen year male patient facture left shaft of femur (a), fixed with $\mathrm{K}$ nail (b), Union of facture (c) and final picture after implant removal (d)

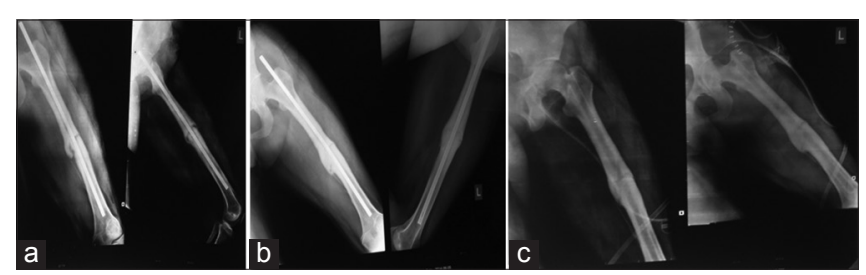

Figure 2: Forty year male patient facture left shaft of femur fixed with $\mathrm{K}$ nail (a), Union of facture (b) and final picture after implant removal (c)

interlocking nail remains the gold standard in treatment of femur shaft fractures; open K- nail still has its relevance in developing countries where facility may not be available.

In our study all the patients treated with $\mathrm{K}$ nail had fracture healing on an average of 17 weeks, which comparable to study of Devanni et al and A SBajwa et al.,7

Partial weight bearing create a micro-movement in $\mathrm{K}$ nail fixation (dynamic system) which help in callus formation and increase in union rate. This might be the reason for healing in all cases in our study.

Average full weight bearing in $\mathrm{K}$ nail patients is much delay as compared to different studies done for Intramedulllary interlocking (IMIL). 
The advantage of IMIL is to prevent shortening and mal-alignment but despite the locking this has not been completely prevented with the report of $1-2 \mathrm{~cm}$ and $10^{\circ}-15^{\circ}$ mal rotation regarding an excellent to good results. ${ }^{8}$ In the current study, in 14 patients the limb was shortened by $1-2 \mathrm{~cm}$ and in two patients it was by $3 \mathrm{cms}$, though it did not affect their gait. Rotational mal-alignment was not seen in our study as all cases were done by OPEN reduction and had good cortical opposition of fracture ends. Clover leaf configuration, inter- digitations of fragments helps in prevention of rotation. ${ }^{9}$ In our study Fracture heals on an average of $17.46 \pm 3.87$ weeks range from $12-30$ weeks which is comparable to the union rate of IMIL. Considering the cost and surgical aspect of this treatment, it is thegood option for selected femur fractures where financial and technical support is limited. ${ }^{10}$ Infection and nonunion in literature is reported to occur in between $1.5-10 \%$ cases. In our study infection rate was $5 \%$. Maximum were superficial infection which is similar to the different study done by Hafiz-UR-Rehmanet al. ${ }^{11}$

\section{CONCLUSION}

Kuntscher Nail is still a relevant option for treatment of fracture Shaft of femur in developing countries with good functional and clinical results. $\mathrm{K}$ nail is safe, effective and relevant option where facility of closed Nail not available. Good results seen in transverse and short oblique factures. It is not recommended for severely comminuted and distal $1 / 3^{\text {rd }}$ factures.

\section{RECOMMENDATIONS}

( $\mathrm{K}$ - Nail as option of treatment) Can be used in transverse and short oblique fractures where there is lack of sophisticated instrumentation and no availability of image intensifier in poly-trauma patients where procedure is short. Pregnant female, operative procedure is short, minimal anesthetic toxicity, no requirement of $\mathrm{C}$ - arm and sometime can be used in poly trauma especially pelvis facture cases where traction cannot be applied.

\section{LIMITATIONS OF K-NAIL}

The limitations of K-Nail are, it requires longer recovery time, increases the post-operative stay in hospital, requires blood transfusion in most cases, delay in range of motion, the chances of post-operative infections are higher. Though transverse, short oblique, minimal comminuting fractures are good option for $\mathrm{K}$ nail, for better and adequate stability of severely comminuted fracture, long spiral, short oblique and segmental fracture require intramedullary interlocking.

\section{REFERENCES}

1. Bucholz RW. Rockwood and Green's Fractures in Adults: Two Volumes Plus Integrated Content Website (Rockwood, Green, and Wilkins' Fractures). Lippincott Williams \& Wilkins; 2012 Mar 29.

2. Canale ST andBeaty JH. Campbell's operativeorthopedics. $12^{\text {th }}$ ed. Philadelphia: Mosby; 2012.

3. Winquist RA, Hansen ST and Clawson DK. Closed intramedullary nailing of femoralfractures: a report of five hundred and twenty cases. J Bone Joint Surg 1984;66:529-539.

4. Kuntscher G. The intramedullary nailing of fractures.Clinical Orthop1968; 605-612.

5. Bajwa AS, Schnaid E and Sweet ME. Current indications for open Kuntscher nailing of femoral shaft fractures. East and Central African Journal of Surgery 2000;5(2):11-13.

6. Olasinde. Open Kuntscher Nailing of Closed Femoral Shaft Fractures: Revisited. The Internet Journal of Third World Medicine. 2005. Vol 3 No.2.

7. Devnani AS. Open reamed femoral intramedullary nailingrevisited. Eastern Journal of Medicine 2003;8(1):7-11.

8. Tornetta P, Ritz $\mathrm{G}$ and Kantor A. Femoral torsion after interlocked nailing of unstable femoral fractures. Journal of Trauma and Acute Care Surgery 1995;38(2):213-219.

9. Bong MR, Koval KJ and Egol KA. The history of intramedullary nailing. Bulletin-hospital for joint diseases New York2006;64(3/4):94.

10. Yu CK, Wong HY, Vivek AS and To BS. Unlocked nailing vs. interlocking nailing for winquist type I and II femoral isthmus fractures. Is there a difference?. Malaysian Orthopaedic Journal 2008;2(1):23-27.

11. Rehman HU, Anjum MP and Kaimkhani GM. Interlocking versus kuntscher nails in the management of femoral shaft fractures. Pakistan Journal of Surgery 2007;23(4):265-269.

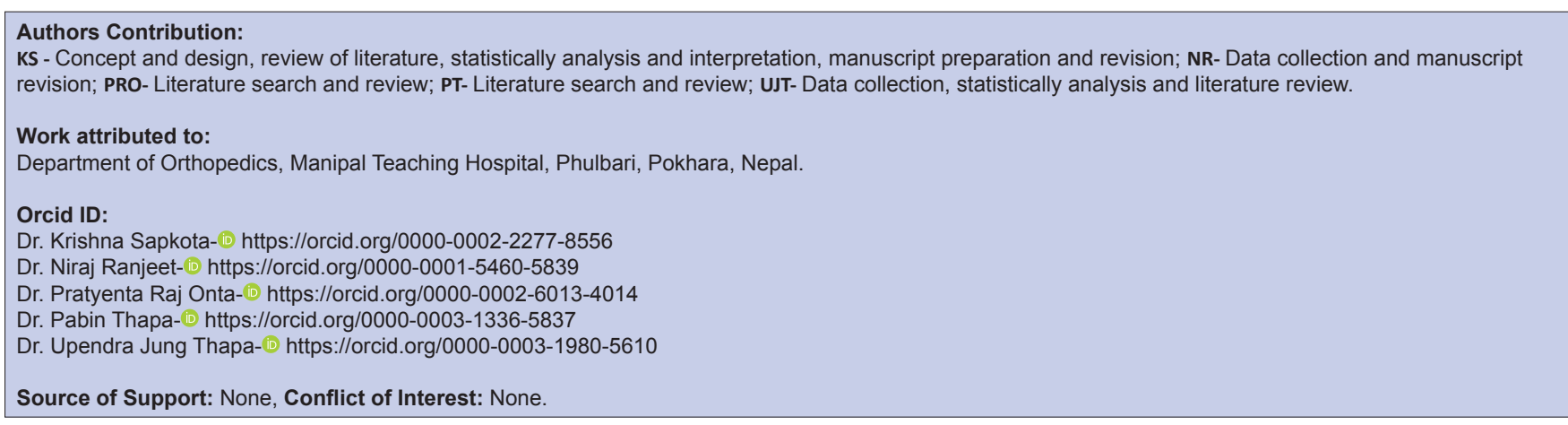

